\title{
ANÁLISIS
}

\section{Coyunturas y recelos de la reinserción internacional de Myanmar}

DOI: $10.32870 /$ mycp.v3i9.470

Carlos Cerda Dueñas ${ }^{1}$

\section{Resumen}

Este artículo se enfoca en analizar el devenir histórico reciente de Myanmar, particularmente su reinserción en el escenario internacional a partir de la demostración de signos de apertura y cambio tras décadas de dictadura militar represiva y aislacionista. Sin embargo, dicha transición expedita, pero inacabada, ha contado de alguna manera con la complacencia de países y algunos organismos internacionales, que parecen mirar de soslayo los muchos pendientes en materia de derechos humanos, democracia y gobernanza que aún prevalecen en la realidad birmana, por lo que se ha generado la interrogante de si han actuado con la convicción de fomentar la regularización de Myanmar en la arena global, o su proceder obedece a cuestiones pragmáticas que buscan, de forma específica, reducir la presencia e influencia china y ocupar

Artículo recibido el 31 de marzo de 2014 y dictaminado el 22 de mayo de 2014.

1. Profesor en el Tecnológico de Monterrey (ITESM), Campus Guadalajara, adscrito al Departamento de Derecho y Relaciones Internacionales. Abogado por la Facultad de Derecho de la Universidad de Guadalajara; maestro en Estudios Diplomáticos por el Instituto Matías Romero de la Secretaría de Relaciones Exteriores de México y doctor en Derecho por la Facultad de Derecho de la Universidad de Buenos Aires, República Argentina. Profesor visitante en la Facultad de Ciencias Jurídicas y Sociales de la Universidad de San Carlos de Guatemala. ORCID http://orcid.org/0000-0001-6860-1943 Correo electrónico: carlos.cerda@itesm.mx 
un espacio del que han estado ausentes durante mucho tiempo, pero que siempre han considerado de vital importancia geopolítica y geoeconómica.

Palabras clave: Myanmar, relaciones internacionales, sudeste asiático, geopolítica, diplomacia.

\begin{abstract}
This article focuses on analyzing recent historical development of Myanmar, in particular its reintegration into the international scenery from showing signs of openness and change after decades of repressive and isolationist military dictatorship. However, this transition is unfinished and it has counted somehow with the complacency of countries and some international organizations, which seem to look askance many pending issues in the field of human rights, democracy and governance. This gives rise to the question if they have acted in the belief promote the regularization of Myanmar in the global arena or their behavior is due to pragmatic reasons in order to seek specifically reduce the Chinese presence and influence and then occupying a space always considered of great geopolitical importance.

Keywords: Myanmar, international relations, Southeast Asia, geopolitics, diplomacy.
\end{abstract}

\title{
Introducción
}

Un lustro le bastó a la República de la Unión de Myanmar² para emerger como un importante actor en el escenario internacional. No es que no lo fuera, pero la ausencia, entre otras cosas, de democracia y de observancia de derechos huma-

2. En idioma birmano, Birmania es Myanma o Bama; de esta última palabra se derivó al inglés, primero Bermah y luego Burma, mientras que se cree que de una mezcla de las dos palabras surgieron las denominaciones en las lenguas romance: Birmanie en francés, Birmânia en portugués y Birmania en español. En la década de 1920, algunos independentistas birmanos llamaban a su patria Myanma, para recordar al reino destruido por los colonialistas británicos el siglo anterior. Después de la independencia en 1948 se adoptó el nombre de República de Birmania. En 1989, la Junta Militar que gobernó el país desde 1962 le cambió el nombre por Myanmar. La oposición política birmana, al no reconocer la legitimidad de la Junta, tampoco aceptó el cambio del nombre del país. Así, lo hicieron también algunos gobiernos como los de Estados Unidos, Canadá, Australia y el Reino Unido. Sin embargo, el cambio de nombre fue reconocido y aceptado por Naciones Unidas, China, Vietnam, Laos, Tailandia, Bangladesh, India y Rusia, entre otros, mientras que la Unión Europea utiliza la salomónica forma de Birmania/Myanmar en sus documentos. Fuente principal: Fernández, 2008. En este artículo se utilizará indistintamente Birmania si son referencias a 
nos le llevaron a ser considerada un Estado paria por el resto de la comunidad internacional, que incluso le aplicó sanciones que, como en todos los casos, perjudicaron más a una población ya de por sí pauperizada, pues a pesar de sus variados y abundantes recursos materiales y humanos, fue y sigue siendo el país más pobre del sudeste asiático. Hoy, Myanmar, la antigua Birmania, cobra una renovada importancia debido a su posición geoestratégica, por compartir fronteras con los dos países más poblados de mundo y porque países occidentales desean ahora tener presencia económica e influencia política en el lugar.

Hay un amplio debate sobre las razones de la rapidez del ritmo de cambio actual de

Hay un amplio debate sobre las razones de la rapidez del ritmo de cambio actual de Myanmar. Tal vez sus dirigentes reconocieron que el país, que llegó a ser el mayor exportador mundial de arroz, estaba rezagándose mucho respecto de sus vecinos. Tal vez escucharon el mensaje de la primavera árabe, o simplemente entendieron que, con más de tres millones de birmanos en el extranjero, era imposible aislar al país del resto del mundo o impedir la entrada de ideas emancipadoras Myanmar. Tal vez sus dirigentes reconocieron que el país, que llegó a ser el mayor exportador mundial de arroz, estaba rezagándose mucho respecto de sus vecinos. Tal vez escucharon el mensaje de la primavera árabe, o simplemente entendieron que, con más de tres millones de birmanos en el extranjero, era imposible aislar al país del resto del mundo o impedir la entrada de ideas emancipadoras. "Cualquiera que sea la razón, el cambio se está produciendo y es innegable la oportunidad que éste representa" (Stiglitz, 2012).

Este artículo se enfoca en analizar el devenir histórico reciente de Myanmar, con énfasis en su reinserción en el escenario internacional a partir de su retorno a la democracia, para lo cual ha contado con el apoyo y complacencia de países y algunos organismos internacionales, otrora sus detractores, que

cuestiones anteriores a 1989, y Myanmar para lo posterior a esta fecha. Tratándose de gentilicios, en todos los casos se empleará el término birmano. 
parecen mirar de soslayo los muchos pendientes en materia de derechos humanos, democracia y gobernanza que aún prevalecen en la realidad birmana, argumentando que su proceder obedece a cuestiones pragmáticas que buscan, particularmente, reducir la presencia e influencia china y ocupar un espacio del que han estado ausentes durante mucho tiempo, pero que siempre han considerado de vital importancia geopolítica y geoeconómica.

\section{Antecedentes}

La región que hoy es la República de la Unión de Myanmar fue el asiento de la monarquía que fundó el rey Anawratha en el siglo XI tras la unificación de los pueblos birmanos. Tras un periodo de guerras que se extendió por aproximadamente 60 años, los británicos completaron la colonización de Birmania hacia 1866, anexándole al Imperio Indio Británico, del cual fue segregado en 1937 cuando se realizaban ya protestas por la presencia colonial de los británicos. El principal de estos movimientos se encontraba encabezado por Aung San, quien tras simpatizar con los japoneses durante la Segunda Guerra Mundial, finalmente se alió y apoyó a los británicos que, una vez terminado el conflicto bélico, concedieron la independencia a Birmania.

La independencia se gestó en dos etapas: se pactó en 1947 y para el año siguiente se concretó el traslado de la soberanía. Aung San lideró un gobierno transicional que negoció y suscribió el Acuerdo de Panglong para unificar a las más importantes etnias de la región. Sin embargo, Aung San y varios miembros de su gabinete fueron asesinados. Los británicos entregaron la soberanía el 4 de enero a $\mathrm{U} \mathrm{Nu}$, miembro del gobierno provisional y considerado como sucesor de Aung San. Sin embargo, los primeros años de vida independiente fueron muy convulsos. Las minorías étnicas aspiraban a obtener su propia independencia.

El Estado birmano no se consolidaba cuando, en 1962, un golpe de Estado encabezado por Ne Win derrocó a Nu. A partir de entonces se estableció una dictadura militar que suprimió cualquier manifestación democrática y llevó al deterioro constante de los derechos fundamentales de la población. Hasta 1988, Ne Win gobernó al país con su programa "Vía birmana al socialismo", una mezcla de principios marxistas y nacionalistas con influencia budista, que en la práctica menoscabó el desarrollo humano del pueblo de Birmania y llevó al país al borde de la bancarrota, generando significativas movilizaciones populares conocidas como el "Verano democrático" que fueron fuertemente 
reprimidas, conllevando centenares de detenidos, a muchos de quienes se les aplicó la pena de muerte.

Los movimientos de protesta y la consecuente represión condujeron a la condena de la comunidad internacional, al corte de la cooperación y culminaron en la destitución de Win, así como a la promesa de los militares de celebrar elecciones democráticas en 1990. En esta época regresa del extranjero a Birmania, Aung San Suu Kye, hija del líder independentista Aung San, que al anuncio de elecciones libres participó en la formación de la Liga Nacional para la Democracia (LND). Suu Kye fue detenida a mediados de 1989. Las elecciones se celebraron conforme a lo prometido en 1990, mismas que no fueron validadas por los militares que siguieron en el poder y desconocieron el triunfo de la LND. Ne Win continuó conservando amplia influencia en la toma de decisiones de los círculos gubernamentales hasta su muerte en 2002.

El desconocimiento de las elecciones intensificó la presión tanto interna como externa hacia la Junta Militar: países occidentales cortaron la ayuda al desarrollo y establecieron embargos; se estipularon sanciones a nivel internacional; se movilizaron los exiliados y organizaciones no gubernamentales con el fin común de lograr la democratización y el respeto a los derechos humanos. Un nuevo movimiento estudiantil de protesta se gestó hacia 1996 y nuevamente fue reprimido con fuerza. Como consecuencia, el presidente de Estados Unidos, Bill Clinton, prohibió cualquier inversión estadounidense en Myanmar.

La noche del 30 de mayo de 2003, el convoy de la Liga Nacional para la Democracia, encabezado por Aung San Suu Kyi fue atacado. Dejó una gran cantidad de muertos y heridos. La violencia generada, los homicidios y la persecución a Suu Kyi atrajeron la atención y condena mundial; la Asociación de Naciones del Sudeste Asiático (ASEAN) ${ }^{3}$ rompió su tradicional silencio, admitiendo incluso que dicho evento tenía un impacto negativo en el organismo regional.

El incidente propició un intenso y ríspido debate al interior de la ASEAN, destacando la postura del entonces primer ministro malasio, Mahatir Mohamed, quien propuso la expulsión de Myanmar en tanto no fuera liberada Suu Kyi. La presión tuvo sus resultados, pues la Junta Militar se vio obligada a efectuar acciones para atenuar la presión y condena pública interna e inter-

3. Las siglas de la Asociación de Naciones del Sudeste Asiático son ANSEA. No obstante, en este artículo se lo utilizará en la versión inglesa ASEAN. 
nacional. Fue así que anunció la llamada "Hoja de ruta hacia una democracia disciplinada”, misma que fue presentada el 30 de agosto de 2003 por el general Khin Nyut en su carácter de primer ministro. Dicho plan contenía, entre otros puntos, la redacción de una nueva Constitución y la convocatoria a elecciones. En agosto de 2007, un incremento en los combustibles incentivó masivas protestas que se conocieron con el nombre de la "Revolución de Azafrán" por el color de la indumentaria de los monjes budistas que iniciaron y participaron activamente en el movimiento. Estas protestas constituyeron el más grande desafío de la población al régimen militar que, desde luego, reaccionó reprimiendo, arrestando e incluso asesinando a algunos manifestantes y emprendiendo una feroz persecución a monjes y civiles sospechosos de haber apoyado, directa o indirectamente, las protestas.

En este contexto, el ciclón Nargis golpeó fuertemente a Myanmar en los primeros días de mayo de 2008. La Junta Militar informó que calculaba en más de 22,500 los muertos y 40,000 los desaparecidos. Los daños del Nargis se concentraron especialmente en la zona arrocera del delta del Irrawaddy. Líderes de países occidentales tuvieron que hacer un llamamiento a la Junta birmana para que aceptara la ayuda humanitaria, que había sido bloqueada. Estos acontecimientos y otros inmediatos subsecuentes propiciaron mayor presión internacional y un cambio de postura de la Junta Militar.

La comunidad internacional, en tanto, dio algunas muestras de preocupación por la situación birmana: en septiembre de 2005, Václav Havel, ex presidente de la República Checa y Desmond Tutu, arzobispo emérito de Ciudad del Cabo y Premio Nobel de la Paz 1984, dieron a conocer un documento sobre Myanmar elaborado, a petición suya, por la firma de abogados DLA Piper Rudnick Gray Cary. El documento generado se tituló Amenaza para la Paz: Un llamado al Consejo de Seguridad para que actúe en Birmania y lo mandaron hacer debido a que consideraban que Myanmar se había convertido en un problema para la región y la comunidad internacional (Havel y Tutu, 2005). El reporte concluía señalando que ya era tiempo de que el Consejo de Seguridad se involucrara en Myanmar (haciendo comparativos con Sierra Leona, Afganistán, Camboya, Yemen, Haití, Ruanda y Liberia). "El Consejo de Seguridad tiene la autoridad para actuar y debería ejercer esa autoridad en el caso de Birmania" (Havel y Tutu, 2005: 58).

En diciembre de 2007 y como efecto de la revolución de Azafrán, se constituyó al interior de Naciones Unidas el denominado "Grupo de Amigos del Secretario General sobre Myanmar", un conjunto de 14 naciones con el 
objetivo de asistirle en sus esfuerzos de fomentar cambios en dicho país. Fue constituido como un foro para desarrollar enfoques comunes en apoyo del mandato de buenos oficios del secretario general; su formato era meramente informal y se encontraba constituido por los cinco países con derecho a veto en el Consejo de Seguridad (Estados Unidos, Reino Unido, China, Rusia y Francia), además Australia, Noruega, Indonesia, Japón, Singapur, Vietnam, Tailandia, India y Portugal.

Las elecciones presidenciales, primeras en 20 años, se celebraron el 7 de noviembre de 2010. Sin embargo, la Constitución reserva $25 \%$ de los escaños para ser nombrados por los militares, por lo que en las elecciones sólo había en juego el restante $75 \%$. El Partido Unión Solidaridad y Desarrollo, próximo al Ejército, ganó $80 \%$ de los escaños restantes. De esta forma, para marzo de 2011 se disolvió la Junta Militar, se convocó a los respectivos parlamentos y se estableció un gobierno civil presidido por el antiguo primer ministro y general, Thein Sein.

\section{La larga "amistad" con China y el regreso a Myanmar de viejos actores}

Myanmar es el segundo país más grande del sudeste asiático después de Indonesia. Es el décimo país con las reservas de gas natural (2.5 trillones de metros cúbicos), que incluyen 510 trillones de reservas probadas. Myanmar es líder en la producción de piedras preciosas, zafiros, rubíes y diamantes. También es un importante productor de oro. Produce metales raros, perlas y nefritas (Ignatchenko, 2012). El jade es uno de sus principales productos de extracción. También posee amplias hectáreas de bosque, selva y tierra cultivable que alguna vez le posicionó como el primer productor mundial de arroz. Su litoral de casi dos mil kilómetros de extensión y sus recursos marinos también son de importante consideración. La posición geográfica de Myanmar le inviste de significativa importancia geoestratégica y le hace atractivo a diversos países del entorno y aquellos que tienen o desean tener influencia en la región. Este papel lo desempeñó China durante los años de la dictadura militar.

Es evidente que China siempre ha tenido un lugar especial en la política exterior de Myanmar. En el contexto de las políticas de reformas y de apertura al mundo exterior emprendidas en China por Deng Xiaoping, los consejeros políticos chinos enfatizaron el significado de la posición geográfica de Myan- 
mar a principios de la década de los ochenta (Haacke, 2012). Dicho espíritu se reflejó en la época del gobierno militar, cuando la relación bilateral fue muy intensa: el primer ministro Li Peng visitó Myanmar en 1994 y el entonces presidente Jiang Zemin hizo lo propio en 2001. El vicepresidente Xi Jingping hizo gira por Myanmar en 2009. El primer ministro Wen Jiabo viajó a Myanmar en junio de 2010 en el marco de la celebración del sexagésimo aniversario del establecimiento de relaciones diplomáticas entre los dos países. En el periodo de aislamiento, China fue un aliado fiel al Gobierno birmano.

Durante las décadas en las cuales varias administraciones estadounidenses buscaron poner fin al régimen militar, China emergió como el mayor inversionista extranjero en Myanmar, un socio comercial estratégico y una significativa fuente de financiamiento y conocimiento (Haacke, 2012), pero fue particularmente a principios de este siglo cuando los chinos acordaron la construcción de obras mayores de infraestructura.

En el terreno diplomático, el apoyo fue más que evidente en Nueva York; Pekín propuso que el Grupo de Amigos de Myanmar en las Naciones Unidas asumiera un más práctico papel para fortalecer el desarrollo económico del país. En tanto, en el periodo 2006-2007 China proporcionó a Naypyidaw un importante respaldo diplomático, toda vez que Washington y Londres afirmaron que Myanmar planteaba una amenaza a la paz y estabilidad regional. Esto culminó con el doble veto chino-ruso en enero de 2007 del borrador de una resolución presentada por Washington y Londres ante el Consejo de Seguridad.

Debe considerarse que $85 \%$ del petróleo y sus productos son abastecidos a China desde el Golfo Pérsico y África a través del Océano Índico, incluyendo el angosto Estrecho de Malaca controlado por las fuerzas armadas de Estados Unidos y sus aliados regionales. Área que además está sujeta a ataques piratas (Ignatchenko, 2012); por esto, Myanmar se vuelve tan importante para China, pues puede ser una vía corta y segura de salida al Índico.

En marzo de 2009 los dos países suscribieron un acuerdo para la construcción de un oleoducto con valor de 2.5 mil millones de dólares y una longitud de 2,380 kilómetros, así como un gasoducto de 2,806 kilómetros que conectará la ciudad birmana de Kyaukpyu con las provincias sudoccidentales de China.

Billy Tea (2010: 9) señala, por su parte, que las relaciones chinas con el Gobierno en el poder son para garantizar la seguridad en la frontera y proteger sus inversiones. Que, efectivamente, le permitirá ser menos dependiente del Estrecho de Malaca y asegurar su acceso al Océano Índico. Ciertamente, el otro interés tradicional que los chinos tienen a lo largo de la frontera es 
la estabilidad. Las autoridades chinas han velado por contener los efectos secundarios de los enfrentamientos entre milicias armadas de los grupos étnicos Kachin y Karen y el gobierno de Myanmar.

Pero no todo es concordia en las relaciones sino-birmanas: llegado un momento, la creciente dependencia económica de China de cara a las sanciones de Occidente llegó a ser la mayor preocupación de los líderes militares de Myanmar (Haacke, 2012). Actualmente, la preocupación no es menor; además de la conciencia que supone el acercamiento a Occidente para efectos de la reinserción en el escenario internacional, el Gobierno birmano pretende atraer inversiones, turismo y comercio de dichos países con el propósito de disminuir la influencia china.

Ya en el pasado y durante el régimen militar se dio muestras de ello: la dictadura planificó, en algún momento, desarrollar energía nuclear, posiblemente para con ello fortalecer su posición en la región y también buscando encontrar algún uso para el uranio obtenido como subproducto de las minas de oro del país. Lo cierto es que en ausencia de demanda doméstica de dicho mineral, en su mayoría es exportado a China; también podría estar siendo usado para comercio en especie con Corea del Norte.

En el año 2000 Myanmar solicitó asistencia del Gobierno ruso para la construcción del centro de investigación nuclear, planeándolo establecer cerca de la ciudad de Magwe, en la parte central del país y creando el Departamento de Energía Nuclear que quedó adscrito al Ministerio de Ciencia y Tecnología de Myanmar. El 15 de mayo de 2002 el Gobierno ruso emitió la resolución 312 relativa a la "firma de un acuerdo entre el Gobierno de la Federación Rusa y el Gobierno de Myanmar en materia de cooperación en la construcción de un centro de investigación nuclear en Myanmar". Dicho tratado comprendía el diseño y construcción del centro de investigación nuclear, así como la capacitación de los especialistas de Myanmar para el centro de investigación nuclear.

Sin embargo, las consultas entre Rusia y Myanmar sobre la implementación del acuerdo se vieron interrumpidas en el otoño de 2007 debido a la inestabilidad en Myanmar conocida como la Revolución del Azafrán. Las consultas no han sido reanudadas y Myanmar todavía no firma el protocolo adicional de la Organización Internacional de la Energía Atómica. Ha sido de llamar la atención el hecho de que hayan elegido a Rusia y no a China para este proyecto. "Parece ser que Rusia, que tiene larga experiencia en la capacitación de especialistas nucleares, fue percibido por Myanmar como un contrapeso 
para China, desde la visión de Myanmar de una presencia china demasiado activa en el país" (Khlopkov y Konukhov, 2011: 4).

La suspensión que hizo el presidente U Thein Sein de la construcción de la represa hidroeléctrica Myit Sone en el estado de Kachin "[...] fue interpretada como un gesto simbólico en contra de la predominante influencia china" (Haacke, 2012: 57), pero dicha decisión se adoptó, oficialmente, debido al daño ecológico que los chinos estaban infligiendo al medio ambiente de la región. Otro factor que no se debe soslayar es que en Myanmar hay resentimientos hacia los chinos, algunos generados por el hecho de que las obras se realizan con mano de obra china sin contratar a trabajadores locales, que sólo ven generación de empleo de la cual no son beneficiarios. Además algunas compañías mineras de Myanmar están relacionadas, directa o indirectamente, con empresarios chinos (Win, 2012) y cada año toneladas de jade son exportadas ilegalmente al mercado negro de China.

Para los chinos vender piedras y madera de Myanmar es sólo cuestión de negocios, pero para muchos birmanos esto representa nada menos que el saqueo de su país. Los birmanos alegan que mientras los hombres de negocios chinos de Yunnan han hecho fortunas a través de sus importaciones, muchas veces en complicidad con funcionarios birmanos corruptos, la mayoría de los birmanos se han beneficiado muy poco del comercio transfronterizo. Los chinos no percibieron cómo se acumulaba el resentimiento hacia su presencia y la explotación económica de Myanmar. Zhu Feng, profesor de relaciones internacionales en la Universidad de Pekín, señala que el error chino en Myanmar fue centrarse únicamente en construir relaciones con los gobiernos oficiales, sin prestar atención a los matices políticos locales. Los chinos locales saben muy poco acerca de Myanmar y lo que saben se limita al hecho de que Myanmar es pobre y según creen, peligroso (The Economist, 2012).

La dependencia de China ha causado incomodidad entre sus líderes, dada la complejidad de la relación entre los dos países. Pekín ha sido el apoyo del Gobierno, al tiempo que respalda a los rebeldes kachin a lo largo de la frontera sino-birmana, señaló Hugo Williamson, director del Grupo de Resolución de Riesgos, un grupo consultor británico (Han Shih, 2013). En contrapartida, a China le preocupa la región puesto que el Triángulo Dorado, que incluye a Myanmar, ha sido el centro de comercio de opio y heroína desde los ochenta, y hoy, 95\% de la heroína en China proviene de esta región.

Con todo, la presencia e influencia china es innegable; China promovió una asociación integral estratégico-cooperativa, la cual fue formalmente suscrita 
durante la primera visita de U Thein Sein como presidente a Pekín en mayo de 2011. Asimismo, interlocutores chinos han continuado facilitando el diálogo entre el Gobierno y algunos grupos étnicos armados. El presidente U Thein Sein ha señalado que China es un buen vecino y un buen amigo de Myanmar, y que las relaciones diplomáticas con China son las más cercanas y las más importantes de Myanmar. Lo dijo así el 24 de junio de 2013, cuando recibió al consejero de Estado y ex ministro de relaciones exteriores chino, Yang Jiechi.

Sin embargo, la participación en el mercado birmano de las compañías chinas podrá disminuir con la llegada de inversiones de Occidente, pero los recursos en efectivo contribuirán a mantener la influencia. China, el mayor inversionista en Myanmar. China podrá perder mercado frente a otros países deseosos de invertir en dicho país, pero la mayor economía de Asia continuará siendo el mayor inversionista. China permanecerá como el mayor inversionista en Myanmar; señaló Tripathi: "hay una ventaja competitiva en la proximidad geográfica y familiaridad con el mercado, pero con el tiempo, China eventualmente descenderá" (Han Shih, 2013).

El consejero de Estado y ex ministro de relaciones exteriores chino, Yang Jiechi, al visitar Naypyitaw en junio de 2013, señalaría que China y Myanmar han sido tradicionalmente vecinos amistosos. Agregó que China respeta la integridad soberana y territorial de Myanmar y que le apoya en su desarrollo. Afirmó también que China espera y apoya la estabilidad social, el desarrollo económico y el mejoramiento de la calidad de vida en Myanmar. Indicó que China apoya el proceso de reconciliación nacional y espera que tanto el Gobierno de Myanmar como la parte kachin puedan mantener las negociaciones de paz y puedan suscribir un acuerdo de cese al fuego lo más pronto posible que traiga consigo la estabilidad y la paz duradera en la parte norte del país a lo largo de la frontera con China, para lo cual China está dispuesta a continuar cumpliendo un papel constructivo al respecto. De acuerdo con Li Chenyang (2012: 66):

Myanmar es un país con un fuerte nacionalismo y orgullo nacional, a la vez de poseer una profunda tradición de diplomacia neutral. Sin importar cuan profunda sea la relación con China, no le permitirá instalar bases militares en sus costas. En particular no le permitirá usarlas en contra de la India.

Hay diversas razones de los dos países para establecer una sociedad estratégico-cooperativa integral. Desde la perspectiva china, en primer lugar, su 
política hacia Myanmar ha ido en concordancia con el plan propuesto en la búsqueda de un ambiente externo estable para su modernización y desarrollo. Segundo, China quiere expresar su apoyo al nuevo Gobierno y, tercero, el mejoramiento de las relaciones bilaterales puede promover la cooperación económica y sociocultural. Para Myanmar, una relación más estrecha entre el nuevo Gobierno y un miembro permanente del Consejo de Seguridad de las Naciones Unidas ayudará a consolidar al nuevo régimen, promover su estatus internacional y obtener mayor ayuda al desarrollo (Li, 2012). Al fortalecer China su presencia en este país, garantiza su acceso a uno de los más importantes y estratégicos carriles marítimos en el mundo (Ignatchenko, 2012). Al final, cobra importancia la premisa de que "China no quiere en su frontera un Estado orientado a Estados Unidos, pero tampoco quiere un paria del mundo en su frontera" (Tea, 2010: 13).

\section{Estados Unidos busca hacerse del espacio}

Ahora bien, la mesurada apertura de Myanmar y los recelos generados por China tanto en el Gobierno como en la población han abonado para un terreno fértil en el cual Estados Unidos intente disminuir la presencia de los chinos $y$, en consecuencia, aumentar la propia. Lo anterior, no obstante lo señalado por Hillary Clinton cuando fungía como secretaria de Estado estadounidense: "Desde nuestra perspectiva, no estamos viendo esto [el acercamiento a Myanmar] a la luz de cualquier competencia con China" (Haacke, 2012: 53).

Pero lo cierto es que Estados Unidos se ha acercado de forma significativa a Myanmar: el presidente Barack Obama al visitar la Universidad de Yangon durante su gira a Myanmar en noviembre de 2012, dijo a los estudiantes:

\footnotetext{
Vine aquí por la importancia de su país. Ustedes viven el cruce de caminos entre el Este y el Sur de Asia. Ustedes limitan con las naciones más pobladas del planeta. Tienen una historia que se remonta a miles de años y la capacidad de determinar el destino de la región del mundo con más rápido crecimiento (The White House, 2012a).
}

La visita de Obama es la primera de un presidente estadounidense a este país. Su visita se convirtió en un hito y está calificada de "histórica". Conllevó un fuerte respaldo al gobierno de Sein. Durante su estancia en Yangón, Obama 
se entrevistó con Aung Suu Kyi y anunció el regreso de la Agencia de Cooperación, USAid, con su correspondiente política de ayuda.

En 2009, la entrante administración de Barack Obama comenzó una revisión integral de la política de Estados Unidos hacia Myanmar encaminada a la adopción de una más pragmática, pero aun así una política de principios de compromiso cara a cara con Naypyidaw. ${ }^{4}$ La administración Obama sugirió que su política hacia Myanmar fundamentalmente se soporta en la búsqueda de la democracia y los derechos humanos, así como la estabilidad y una mayor prosperidad (Haacke, 2012). En noviembre de 2011 la secretaria de Estado Hillary Clinton visitó Myanmar, 55 años después de que lo hubiera hecho por última vez un funcionario de tal cargo, como lo fue John Foster Dulles. En esta visita, no exenta de críticas tanto al interior de Estados Unidos como internacionalmente, se anunció oficialmente la nueva fase en la relación bilateral.

El embajador Dereck Mitchell fue nombrado en 2011 representante especial y coordinador político para Birmania y después asumió el largamente vacante puesto de embajador de Estados Unidos en Birmania. Bajo la administración Obama, el diálogo se constituyó como un importante complemento a las sanciones. Oficiales estadounidenses han discutido tanto con el Gobierno como con los grupos étnicos el tema de la reconciliación nacional.

\begin{abstract}
El día de hoy marca el comienzo de un nuevo capítulo en la relación entre Estados Unidos y Birmania. Desde que anuncié la nueva apertura de Estados Unidos a Birmania en noviembre [de 2011], el presidente Thein Sein, Aung San Suu Kyi y el pueblo birmano han logrado un significativo progreso en su largo camino a la democracia. Estados Unidos se ha comprometido a responder a los desarrollos positivos en Birmania y a demostrar de forma clara el compromiso de Estados Unidos en el futuro de este extraordinario país, su valiente pueblo y los valores universales. Eso es lo que estamos haciendo (The White House, 2012b).
\end{abstract}

Enseguida señaló que estaba nominando al primer embajador estadounidense en Birmania en 22 años. Sin embargo, señaló:

4. En noviembre de 2005, el gobierno militar trasladó oficialmente la capital de Yangón (Rangún) a Naypydaw, también escrita como Nay Pyi Taw. Algunos utilizan la versión castellanizada de Naipyidó, pero la Real Academia de la Lengua no se ha pronunciado al respecto. La palabra quiere decir "Lugar de Reyes" y se localiza a 350 kilómetros al norte de Yangón, y en la misma zona de la ciudad de Pyinmana, sede del Ejército Independentista Birmano que obtuvo la independencia del Reino Unido en 1948. Hasta marzo de 2013, las embajadas acreditadas en Myanmar seguían establecidas en Yangón. 
[...] por supuesto, esto está muy lejos de estar hecho. Estados Unidos permanece preocupado por el cerrado sistema político birmano, su trato a las minorías y la detención de presos políticos, así como de sus relaciones con Corea del Norte. Continuaremos presionando porque aquellos que cometan violaciones serias de derechos humanos sean señalados como responsables (The White House, 2012b).

El mes previo a la visita de Obama a Yangón, la administración estadounidense sostuvo su primera reunión bilateral con autoridades birmanas con el tema central de los derechos humanos. La delegación de Estados Unidos estuvo encabezada por Michael Posner, asistente de la Secretaría de Estado para Democracia, Derechos Humanos y Trabajo. El propósito del diálogo era abrir un nuevo canal entre los dos países para discutir a alto nivel "temas urgentes y delicados que hubieran sido impensable tratar hace un año" (Power, 2012). La delegación estadounidense estuvo compuesta además, entre otros, por oficiales de la Casa Blanca, la Vicepresidencia, la Agencia de Cooperación (USAid), del Departamento de Seguridad Nacional y del de Defensa.

Un punto muy importante que resaltar es el hecho de que la cooperación militar nunca se interrumpió ni aun en la época de las sanciones económicas; de hecho, se había fortalecido después del golpe de 1988 que abandonó la orientación socialista del Gobierno. "Muchos jóvenes oficiales, que hoy ostentan el grado de generales, recibieron entrenamiento en academias militares de Estados Unidos" (Ignatchenko, 2012). Militarmente, Myanmar recibió la invitación de parte de Estados Unidos para comparecer como observador en el "Cobra Dorada". Dicha operación es el más grande ejercicio militar de la región que cuenta con participación estadounidense. La invitación se considera una especie de respuesta a la iniciativa de Pekín de comenzar patrullajes conjuntos a lo largo del Río Mekong con el objetivo de combatir la piratería en Myanmar, Tailandia y Laos (Ignatchenko, 2012). De esta manera, Myanmar participó, en 2013, durante la trigésima segunda edición del ejercicio que comenzó como una práctica bilateral de Estados Unidos y Tailandia, pero que se amplió hace poco más de 10 años a otros países asiáticos como Japón, Corea del Sur, Indonesia, Malasia y Singapur. Una veintena de países también participan en calidad de observadores, para 2013 por vez primera, Myanmar. La vocera de la Embajada de Estados Unidos en Tailandia, Kristin Kneedler, declaró que la participación de Birmania en los 10 días que se prolongó el ejercicio fue limitada, pero que Estados Unidos valoraba su compromiso, al que calificó de "significativo" (Schearf, 2013). Señalando también que la par- 
ticipación de Myanmar en eventos como éstos "contribuyen a que las fuerzas armadas institucionalicen el control civil, la transparencia y la protección de los derechos humanos".

Al comparecer, en mayo de 2013, ante la Comisión de Derechos Humanos de la Cámara de Representantes, W. Patrick Murphy, representante especial y coordinador de Política para Birmania en la Secretaría de Estado, expresó:

El país ha encarado conflictos internos desde la Segunda Guerra Mundial, sufriendo 50 años de gobierno militar, y quedando muy lejos aún de sus más pobres vecinos. Tenemos, sin embargo, una oportunidad histórica de ayudar a Birmania a solidificar su progreso y fortalecer a aquellos que procuran una reforma más profunda, del tal suerte que este proceso se vuelva irreversible (Murphy, 2013).

Por otra parte, el 20 de mayo de 2013 el presidente Obama recibió en la Casa Blanca al presidente de Myanmar, en lo que constituía la primera visita de un jefe de Estado de aquel país en 50 años; señalando Obama que durante dicho periodo "ha habido significativas tensiones bilaterales entre nuestros dos países, pero lo que ha permitido este cambio es el liderazgo que el presidente Sein ha mostrado al llevar a su país en la ruta de reformas políticas y económicas" (Slack, 2013). Al recibir a Thein Sein en la Casa Blanca, el presidente Obama señaló en su intervención que

También compartí con el presidente Sein nuestra profunda preocupación acerca de la violencia comunal que ha sido dirigida a las comunidades islámicas al interior de Myanmar. El desplazamiento de gente y la violencia dirigida hacia ellos necesita detenerse, y estamos preparados para trabajar de todas las formas que podamos con el Gobierno de Myanmar y la comunidad internacional para asegurar que el pueblo reciba la ayuda que necesita, pero, lo más importante, que sus derechos y su dignidad sean reconocidos (The White House, 2013).

La nueva relación con Washington no sólo ha servido para ayudar en la legitimación del gobierno entrante, sino también ha permitido a los líderes de Myanmar dejar de lado la representación de un país considerado como Estado paria en la sociedad regional e internacional. También, y es la meta, han contribuido a un más amplio balance de las relaciones exteriores de Myanmar. Países que al principio fueron persuadidos o presionados por Washington para ejercer un papel duro en contra del gobierno militar, han reconsiderado su posición hacia Naypyidaw. 
Estados Unidos sabe que Myanmar se está convirtiendo en la arena para ejecutar un "gran juego" que le lleve a ganar influencia geopolítica en el sudeste asiático (Ignatchenko, 2012). Como también muchos en China consideran que el cambio de Estados Unidos en su política hacia Birmania es parte de un esfuerzo mayor de cercar y contener a China. ${ }^{5}$

\section{La Unión Europea hace lo propio}

Especial relevancia reviste la relación con la Unión Europea (UE). La UE acompañó el proceso internacional en contra del régimen militar y también impuso sanciones económicas, cuestionadas por su ineficacia y por haber generado la "marginalización de la interacción e influencia europea en Myanmar, particularmente respecto de países, primeramente de China, pero también de otros como India, Tailandia o Rusia" (Frittin y Swanström, 2010). Las sanciones fueron suspendidas en abril de 2012 y levantadas en 2013 (con excepción del embargo de armas). En julio de 2013, la UE restableció el acceso al Sistema Generalizado de Preferencias, el cual implica exención de impuestos y una cuota de libre acceso de productos birmanos al mercado europeo.

La UE fijó como parte de sus objetivos y políticas hacia Myanmar, la dominante meta de apoyar al Gobierno civil a avanzar en el desarrollo económico y social del país, respetando los derechos humanos y reconstruyendo sus relaciones internacionales. Con esta premisa, el presidente de la Comisión Europea, José Manuel Durão Barroso, visitó Myanmar en noviembre de 2012, señalando que su presencia en el país era un testimonio del apoyo de la UE a los trascendentales cambios emprendidos, así como un signo de apoyo y estímulo a la continuación de dichas reformas y la expresión del deseo de apoyar dicho proceso. El Consejo de Relaciones Exteriores de la UE adoptó, en julio de 2013, un "marco integral" que describe la política y el apoyo de la Unión al proceso de apertura y democratización de Myanmar, identificando como áreas de compromiso la paz, la democracia, el desarrollo y el comercio.

El Grupo de Trabajo UE-Myanmar se estableció en noviembre de 2013 en Yangón con la presencia de Catherine Ashton, alta representante de la Unión Europea para Asuntos Exteriores y Política de Seguridad y vicepresidenta de la Comisión Europea. Dicho Grupo se acordó en la visita de Thein Sein a Bruselas

5. Irónicamente, China facilitó un diálogo sin éxito entre oficiales de Myanmar y Estados Unidos en 2007. 
en el anterior mes de mayo. La reunión comprendió tres grandes foros: uno de negocios, uno de la sociedad civil y el tercero, sobre desarrollo. También se realizó una reunión interparlamentaria. Como ejemplo de resultados concretos, podría señalarse que en el Foro de Desarrollo se anunció un paquete de ayuda financiera en el orden de los 200 millones de euros y se estableció el compromiso que para el periodo 2014-2020, Myanmar sería uno de los mayores países beneficiarios de los programas de cooperación de la UE en Asia. El Grupo de Trabajo "es la más visible expresión de la fuerte asociación entre la UE y Myanmar, y nuestro compromiso conjunto de avanzar en las reformas en Myanamar" (Ashton y Thane, 2013).

Los temas de derechos humanos y la democratización seguirán siendo puntos centrales en la agenda bilateral, toda vez que son cuestiones que atraen mucho a gobiernos, ONG y la sociedad civil europea, sobre todo cuando están involucrados recursos económicos de la UE.

El rápido crecimiento de la relación de la UE con Myanmar se ha traducido en el arribo de inversiones europeas. Muchos observadores han señalado que las políticas gubernamentales de Myanmar dirigidas al incremento y mejoramiento de sus relaciones con Europa (y otras naciones industrializadas) tienen como objetivo reducir la dependencia económica del país con China, aunque ello conlleve "importantes riesgos geopolíticos" (Matsui, 2014).

Como lo señalaba el comunicado de prensa del Consejo de la UE en su reunión de relaciones exteriores en abril de 2013: "la UE está dispuesta a abrir un nuevo capítulo en su relación con Myanmar/Burma, construyendo una asociación duradera y promoviendo un compromiso más cercano con el país como un todo" (Council of the European Union, 2013a).

Por otra parte, algunos países miembros de la Unión Europea han desplegado una intensa actividad para fortalecer su relación a nivel bilateral con Myanmar: por razones históricas, el Reino Unido ha sido uno de los pioneros. El primer ministro, David Cameron, visitó el país en abril de 2012, convirtiéndose en el primer líder occidental en hacerlo tras la salida del régimen militar; el presidente birmano pagó la visita en junio de 2013. El Gobierno británico financia en gran parte la realización del censo (programado para celebrarse durante 2014) y ha iniciado un programa de intercambio militar. En enero de 2014 viajó a Myanmar la princesa heredera María Elizabeth de Dinamarca, contexto en el cual el Gobierno danés anunció la condonación de la deuda birmana; al mes siguiente, el presidente alemán Joachim Gauck realizó una visita de Estado. 


\section{Otros actores cumplen su papel}

La reinserción de Myanmar como actor internacional de pleno derecho no se limita exclusivamente a sus relaciones con China y Estados Unidos, y en esta "aparente" competencia por ser más influyente, otros actores cumplen un importante papel al respecto, por ejemplo la Asociación de Naciones del Sudeste Asiático (ASEAN).

El ingreso de Myanmar a dicho organismo regional, en 1997, fue controvertido y criticado por ciertos miembros de la comunidad internacional. El entonces primer ministro de Malasia, Mahatir Mohammed, declaró que "si Myanmar está fuera [de ASEAN] es libre de comportarse como Estado canalla o paria, pero mientras esté dentro, estaría sujeta a ciertas normas de conducta" (Havel y Tutu, 2005: 36). También consideraba que el régimen militar dañaba la imagen de la ASEAN en su conjunto. Hoy, la situación es radicalmente diferente y los países de ASEAN están entusiasmados de que Naypyidaw refuerce el regionalismo en el sudeste asiático, mientras que Myanmar considera que la ASEAN tiene una importante función política para sus fines (Haacke, 2012). La proximidad geográfica, las similitudes culturales y la situación de seguridad comparable, llevaron a los fundadores de la ASEAN a invitar a Birmania a unirse a la Asociación cuando ésta fue concebida, pero rechazó la invitación debido a considerarle "imperialista". Eso llevó a dos décadas de indiferencia, lo que se conjuntó con el aislacionismo birmano.

En julio de 1993 se creó el Foro Regional de ASEAN (actualmente lo integran Australia, Bangladesh, Brunei, Darussalam, Camboya, Canadá, China, Corea del Norte, la Unión Europea, India, Indonesia, Japón, Laos, Malasia, Mongolia, Myanmar, Nueva Zelanda, Pakistán, Papúa-Nueva Guinea, Filipinas, Corea del Sur, Rusia, Singapur, Sri Lanka, Tailandia, Timor-Leste, Estados Unidos y Vietnam). En 1994, el primer ministro tailandés invitó al ministro de Exteriores birmano a que asistiera como observador a la reunión de ASEAN en Bangkok. En dicha reunión el Gobierno de Australia presentó una lista de puntos que Myanmar debía conseguir para mejorar su estatus diplomático. Uno de los puntos era la inmediata liberación de Aung Sang Suu Kyi.

En 1995, Myanmar comenzó a dar señales de querer acceder a la ASEAN y una de ellas fue la puesta en libertad de la Premio Nobel. Durante la Quinta Reunión Cumbre de ASEAN en Bangkok se presentaron los potenciales países a conseguir la membresía: Myanmar, Camboya y Laos. En julio de 1996, Myanmar fue admitido como miembro del Foro y como observador 
en la ASEAN. En 1997, se convirtió en miembro de pleno derecho. La ASEAN también ha sido criticada porque sus países miembros han estado largamente comprometidos con el deseo de promover el crecimiento económico regional y la prosperidad, más que en compartir valores de gobernanza, democracia o los derechos humanos. Algunos países que no son miembros de la ASEAN critican su enfoque basado en el "compromiso constructivo" cuando analizan las prácticas en materia de derechos humanos de sus Estados miembros, enfoque que califican de débil e ineficaz, particularmente en su posición respecto del régimen militar de Birmania (Staggs, 2009).

Myanmar era, hasta 2014, el único país miembro de la ASEAN que no había ocupado la presidencia. A Myanmar le correspondía presidir en 2006 la ASEAN, lo cual preocupó a varios de los países miembros. Singapur, Filipinas, Indonesia y Malasia presionaron para que declinara la presidencia, "particularmente preocupados con la credibilidad de la ASEAN" (Havel y Tutu, 2005: 37). Sin embargo, la asumió para 2014. La presidencia de ASEAN le rendirá mucha de la necesitada legitimidad política al régimen de Naypyidaw y podría ser un factor fundamental en la política interna de Myanmar, favoreciendo a la élite gobernante y ejercer influencia en los resultados de la elección (Chachavalpongpun, 2013).

Myanmar podría gradualmente convertirse en el "nuevo tigre económico" de la región, por lo que asignarle la presidencia parece racional. Con todas las oportunidades empresariales disponibles y la apertura económica, Myanmar podría representar la esperanza y la posibilidad para ASEAN en una era de comunidad (Chachavalpongpun, 2013). La normalización de las relaciones birmano-estadounidenses ha servido también para renovar los vínculos de Estados Unidos con la ASEAN. Cuando la adopción de la política estadounidense fue anunciada, los países miembros de la ASEAN le acogieron muy favorablemente.

La relación con India también reviste innegable importancia. El Ministerio de Relaciones Exteriores de la India ha establecido que la relación con sus vecinos tiene "alta prioridad", entre otras cosas, porque considera que un sudeste asiático "estable y próspero" contribuirá a la propia estabilidad india, además de que la política vecinal india se centra en el claro entendimiento de que una periferia pacífica es esencial para que la India pueda conseguir sus diversas metas de desarrollo.

No debe dejarse de lado que Birmania fue parte del Imperio Indio Británico hasta 1937, cuando fue separada y establecida como colonia autónoma de 
los británicos. Lo que explica la diáspora india y la intensa interacción entre ambos países. Cuando los generales birmanos se levantaron en 1998, India dio refugio a los activistas que se vieron forzados a exiliarse, lo que provocó un enfriamiento en las relaciones bilaterales, pero en los noventa, factores económicos y de seguridad motivaron a la India a buscar un acercamiento con su vecino. Aunque muchos políticos, académicos y otros sectores indios continuaron mostrando su simpatía y apoyo por Aung San Suu Kyi y las fuerzas promotoras de la democracia, el Gobierno dejó de apoyar a la oposición birmana.

El cambio en la política exterior para establecer el lineamiento de que la India debía poseer una relación cercana con Birmania, independientemente de quien estuviera en el gobierno, le permitiría, entre otras cosas, contener o eliminar el problema de la insurgencia en la parte noreste, donde grupos tenían sus bases a lo largo de los 1,600 kilómetros de frontera común con Birmania, particularmente el Consejo Nacional Socialista de Nagaland o los rebeldes de Manipur; otra razón era su preocupación por la creciente influencia de China en Myanmar y para tener una relación más estrecha en consonancia con su política de acercamiento con los países de la Cuenca del Pacífico. No obstante la política de acercamiento con Myanmar, en noviembre de 2001, 50 parlamentarios indios suscribieron la llamada "Declaración sobre Birmania", exhortando a la Junta Militar a liberar a los prisioneros políticos.

India es el mercado más grande para las exportaciones birmanas; una cuarta parte de las exportaciones van al mercado indio. Se instituyeron las reuniones bilaterales anuales para tratar asuntos relativos a la seguridad, comercio y programas de intercambio cultural y de inteligencia. La Iniciativa del Golfo de Bengala para la Cooperación Multisectorial Técnica y Económica ${ }^{6}$ (Bimstec) y la Cooperación del Mekong-Ganges ${ }^{7}$ han sido foros donde la India ha colaborado con Myanmar para el desarrollo de vínculos de transporte, energía y alcance del comercio en la región. En menor medida, la Asociación

6. La Iniciativa del Golfo de Bengala se creó el 6 de junio de 1997; Myanmar asistió como observador, pero ingresó formalmente en diciembre de ese mismo año. Actualmente la membresía es de siete países: India, Tailandia, Bangladesh, Sri Lanka, Myanmar, Bután y Nepal. Tiene suscrito un acuerdo marco de libre comercio que comenzó su vigencia en 2012 y en 2017 para los países menos desarrollados. Su Secretariado Permanente tiene sede en Dhaka.

7. El Mecanismo de Cooperación Mekong-Ganges se estableció el 10 de noviembre de 2000 en Vientiane. Agrupa a seis países: Tailandia, Myanmar, Camboya, Laos, Vietnam y la India. El énfasis está en cuatro áreas de cooperación: turismo, cultura, educación y transportes. 
del Sudeste Asiático para la Cooperación Regional ${ }^{8}$ (SAARC) ha sido otro foro para la interacción indo-birmana, puesto que Myanmar sólo tiene el estatuto de observador desde 2008.

Durante la visita del primer ministro indio, Manmohan Singh a Myanmar en mayo de 2012 (la primera en 25 años), se firmaron 12 Memorándums de Entendimiento que incluyen una línea de crédito por 500 millones de dólares, un acuerdo de espacios aéreos y de desarrollo en la zona fronteriza. De acuerdo con la Cancillería india, Myanmar es un punto central en la política india hacia el Oriente y reconoce que siendo Myanmar el único país de la ASEAN con el que comparte frontera, es su puerta de acceso a la comunidad de dicho organismo regional.

En cuanto a Japón, las relaciones bilaterales pasan por el antecedente de que Japón invadió Birmania durante la Segunda Guerra Mundial y ese hecho fue, de alguna manera, un catalizador para fortalecer el movimiento independentista que logró su objetivo en 1948. Las relaciones diplomáticas se establecieron en 1954 y durante el periodo militar el ministro de Exteriores de Japón visitó Myanmar en 2002. La visita de más alto nivel de un funcionario birmano fue la del actual presidente Thein Sein en su calidad de primer ministro en 2009. Ya como presidente viajó a Tokio en abril de 2012, siendo recibido por su homólogo en aquella fecha, Yoshihiko Noda, quien se comprometió a revisar la política de ayuda internacional japonesa hacia Myanmar; por su parte, Sein se comprometió a dar seguimiento a las investigaciones sobre el homicidio del periodista japonés Kanji Nagai, muerto a manos del Ejército birmano mientras cubría la llamada "Revolución de Azafrán".

En mayo de 2013, el primer ministro de Japón, Shinzo Abe, visitó Myanmar, siendo el primer líder japonés en hacerlo en los últimos 36 años. Durante su encuentro con el presidente Sein Thein en Naypyitaw, se negoció la introducción de tecnología japonesa en Myanmar para ayudar a desarrollar la infraestructura que contribuyera al crecimiento económico. Subrayando la voluntad de Japón para entablar una seria relación de asistencia e inversión con Myanmar. Abe se hizo acompañar por más de 100 representantes de cerca de 40 compañías japonesas que buscaban establecer lazos con el Gobierno y

8. La Asociación del Sudeste Asiático para la Cooperación Regional, en inglés South Asian Association for Regional Cooperation (SAARC) se creó en 1985 y la integran Bangladesh, Bután, India, Maldivas, Nepal, Pakistán y Sri Lanka. Su objetivo: la cooperación agrícola, desarrollo rural, meteorología, salud y actividades poblacionales. Su Secretaría General se encuentra en Katmandú, Nepal. 
con líderes de negocios. Pyone Cho, líder de un prominente grupo activista de la generación del 88, declaró que era tiempo de que Myanmar escogiera inversionistas "más creíbles" (Thura, 2013) como los japoneses y en abierta alusión a los chinos. La creciente insatisfacción con China, señalan los analistas, es algo que Japón puede explotar a través de las inversiones que creen oportunidades de trabajo e incrementen el papel de las pequeñas y medianas compañías en la economía (Thura, 2013).

El mayor proyecto japonés en Myanmar es la Zona Económica Especial de Thilawa en los suburbios al suroeste de Yangón. En abril de 2012, los gobiernos de Japón y Myanmar suscribieron un acuerdo para crear el plan maestro de la zona, dijo Thurane Aung (Han Shih, 2013). Compañías birmanas poseen 51\% del proyecto, en tanto que compañías japoneses detentan el restante $49 \%$. El proyecto comprenderá un puerto y 2,400 hectáreas de zona industrial. Kenneth Stevens, socio gerente de Leonard Capital, una empresa de inversión asiática, afirma que "Thilawa llevará un largo tiempo en su desarrollo, porque los japoneses son inversionistas muy cautos" (Han Shih, 2013). Por otra parte, en mayo de 2013 el primer ministro de Japón, Shinzo Abe, visitó Myanmar, siendo el primer líder japonés en hacerlo en los últimos 36 años. Su visita podría obedecer, según lo señalaron algunos analistas, "para contrarrestar la fuerte influencia china en el país del sudeste asiático" (Thura, 2013).

Finalmente, cabe señalar que dentro de este panorama de reinserción birmana a la regularización de su interacción con el exterior, también ha tocado al sistema de Naciones Unidas: en mayo de 2012, el Programa de Naciones Unidas para el Desarrollo (PNUD) anunció la normalización de sus trabajos en Myanmar. Ajay Chhibber, asistente del secretario general de Naciones Unidas y director de la Oficina Regional para Asia Pacífico del PNUD, viajó al país para discutir con las autoridades el nuevo programa para el país. Asimismo, el PNUD propuso el incremento de la ayuda a Myanmar para apoyar la transición histórica del país, señalando que se requería mayor ayuda así como una mejor coordinación en la alineación con las prioridades de desarrollo de Myanmar. Chhibber también viajó a Yangón para discutir con Aung San Suu Kyi el nuevo programa nacional del PNUD.

En Washington, el 1 de noviembre de 2012 el Directorio Ejecutivo del Grupo del Banco Mundial aprobó una nueva estrategia provisional para Myanmar en la que se reafirma el apoyo para las reformas tendentes a mejorar las condiciones de vida de la población de ese país. Dicha estrategia orientará la labor que la institución realizará en Myanmar en el futuro inmediato y en la 
que se hará hincapié en la aceleración del proceso de reducción de la pobreza a través del suministro de ayuda a las instituciones encargadas de la reforma, para que presten mejores servicios a la población en este crucial periodo de transición. "Me resultan alentadoras las reformas que se vienen llevando a cabo en Myanmar, e insto al Gobierno de ese país a proseguir sus esfuerzos", señaló Jim Yong Kim, presidente del Grupo del Banco Mundial.

\begin{abstract}
Esperamos avanzar, como parte de una comunidad mundial unida, en pos de soluciones que den respuesta a las necesidades más urgentes de la población, en especial en esferas tales como salud, educación e infraestructura; además trataremos de desarrollar el sector privado para promover la creación de puestos de trabajo (Banco Mundial, 2012).
\end{abstract}

Myanmar es miembro de la Iniciativa del Golfo de Bengala para la Cooperación Multisectorial Técnica y Económica (Bimstec). También pertenece a la Subregión del Gran Mekong que comprende a Camboya, China (particularmente las provincias de Yunnan y Guanxi), Laos, Tailandia, Vietnam y Myanmar; cuenta con el patrocinio del Banco de Desarrollo Asiático que canaliza mucha de la ayuda recibida de parte de diversos donantes. Se creó en 1992 con un fuerte apoyo japonés y está considerado "quizá como el más exitoso ejemplo de cooperación económica subregional en Asia” (Abonyi, 2012). Sin embargo, no es parte de importantes organismos regionales o internacionales cuya membresía podría ostentar dada su vocación, como la Asociación de la Cuenca del Océano Índico para la Cooperación Regional o el Foro de Países Exportadores de Gas. En la Asociación del Sudeste Asiático para la Cooperación Regional (SAARC) sólo tiene el estatuto de observador. Myanmar ha manifestado su intención de llegar a ser miembro del Foro de Cooperación Económica Asia Pacífico (APEC).

En la parte económica se puede señalar que Myanmar es uno de los 13 países menos desarrollados de la región Asia Pacífico. Asimismo, ocupa el lugar 149 en el índice de desarrollo humano. También es uno de los países del mundo que recibe menos ayuda internacional en proporción a su población e ingreso (Stiglitz, 2012).

Thurane Aung, un participante en la reciente Conferencia sobre Desarrollo Urbano de Myanmar celebrada en Yangón, declaró: "se están moviendo rápido, cada semana leo sobre noticias sobre inversiones estadounidenses en Myanmar. He visto alemanes, franceses y holandeses venir a buscar oportu- 
nidades de negocios en Myanmar" (Han Shih, 2013). Una motivación para las reformas hechas por el Gobierno de Myanmar es que no quiere depender mucho de China, señaló Salil Tripathi, director de Políticas del Instituto para los Derechos Humanos y los Negocios asentado Reino Unido (Han Shih, 2013). Sin embargo, Nicholas You, jefe del Comité para la Campaña "Mejor Ciudad, Mejor Vida" de UN-Habitat señaló: "las empresas estadounidenses y europeas no están invirtiendo en Estados Unidos y Europa. No se puede esperar que inviertan en Myanmar" (Han Shih, 2013). En contraste con las compañías estadounidenses, las compañías chinas que invierten en Myanmar lo hacen pensando a largo plazo (Han Shih, 2013).

\section{Conclusiones}

Durante el periodo de las sanciones económicas a Myanmar se gestó la emergencia de China, y Tailandia en menor medida, como los mayores socios comerciales, los cuales reemplazaron a Estados Unidos. China obtuvo la mayor ventaja, su presencia se fortaleció en muchas áreas, incluida la económica y la diplomática. Actualmente la comunidad internacional ha acompañado el proceso de reformas y transición birmano, pero queda la interrogante de si lo viene haciendo por su compromiso hacia el pueblo de Myanmar o, de forma pragmática, para acceder al mercado o tener presencia e influencia frente a la disminución de otras. También queda la incógnita de saber si una nueva actitud represiva, de amenaza o punitiva por parte del gobierno "democrático" será consentida por la comunidad mundial.

La apertura reciente de Myanmar generalmente es interpretada por estos expertos como una inclinación hacia Occidente. Las relaciones normalizadas con Washington permitirían, por supuesto, que Myanmar busque fuentes alternativas de capital y conocimiento de instituciones financieras internacionales, como Japón y países occidentales (Haacke, 2012).

La aparición de estos actores transnacionales en Myanmar significará, si no la disminución, sí la competencia frente a la penetración china, muy a pesar de que se reivindique cierta independencia y autonomía respecto de ellos. El presidente Thein Sein señaló en su sorprendente discurso de asunción del cargo el 30 de marzo de 2011, que desde la época postindependiente a la fecha, los sucesivos gobiernos han practicado diferentes políticas y conceptos económicos, pero en relación con las relaciones exteriores, todos habían ejercido una política exterior de no alineamiento, independiente y activa, y 
se relaciona con otros países en línea con los "cinco principios de coexistencia pacífica". ${ }^{9}$ Afirmó que:

Nunca estuvieron bajo la influencia de cualquier potencia. Permanecieron neutrales en las relaciones internacionales. Nunca permitieron el despliegue de tropas extranjeras dentro de las fronteras de la Unión. Nunca lanzaron una agresión en contra de algún país o interfirieron en sus asuntos internos. Nunca profirieron amenazas a la paz y seguridad internacionales o regionales (Sein, 2011).

Con todo, hoy las cosas en Myanmar son diferentes.

Cualesquiera sean las razones para la apertura, la normalización en la vida democrática y en el respeto a los derechos humanos, el futuro inmediato será crucial para el futuro del pueblo birmano. El desarrollo económico y la emergencia como potencia media serían las tareas que tendrían que venir después. Como bien ha señalado Joseph Stiglitz (2012), Premio Nobel de Economía en 2001: "la sensación de esperanza en el país es palpable [...] la mayoría de los birmanos sienten que si los cambios se manejan bien, el rumbo del país será irreversible".

\section{Referencias bibliográficas}

Abonyi, George (mayo 22, 2012), "From battlefield to marketplace: The Greater Mekong Sub-region", Fung Global Institute, Real Sector, disponible en http://www.fungglobalinstitute.org/en/battlefield-marketplace-greatermekong-sub-region

Anónimo (abril 19, 2012), "EU to suspend Burma sanctions”, The Guardian, disponible en http://www.theguardian.com/world/2012/apr/19/eu-tosuspend-burma-sanctions

Anónimo (noviembre 15, 2013), “EU-Myanmar business forum starts in Yangon", Mizzima, Economy, disponible en http://www.mizzima.com/ business/economy/item/10571-eu-myanmar-business-forum-starts-inyangon/10571-eu-myanmar-business-forum-starts-in-yangon

9. En abril de 1955, en la Conferencia de Bandung (Indonesia) para discutir el importante asunto de unidad y cooperación, el primer ministro Zhou Enlai, a la cabeza de la delegación china, reiteró los "cinco principios de coexistencia pacífica" promovidos por China: el respeto mutuo de la soberanía y la integridad territorial; respeto mutuo de no agresión; la no injerencia en sus asuntos internos; la igualdad y el beneficio mutuo, y la coexistencia pacífica. 
Anónimo (octubre 6, 2012), "Relations with Myanmar: Less thunder out of China", The Economist, disponible en http://www.economist.com/ node/21564279

Chachavalpongpun, Pavin (enero 14, 2013), "Myanmar Open-up and ASEAN", Prachatai, disponible en http://prachatai.com/english/node/3482

Council of the European Union (abril 22, 2013a), Council conclusions on Myanmar/Burma, disponible en http://trade.ec.europa.eu/doclib/docs/2013/ april/tradoc_151047.pdf

- - (julio 22, 2013b), Comprehensive Framework for the European Union's policy and support to Myanmar/Burma, disponible en http://www.consilium.europa.eu/uedocs/cms_data/docs/pressdata/EN/foraff/138272.pdf

El Banco Mundial (noviembre 1, 2012), "El Grupo del Banco Mundial intensifica su respaldo para las reformas emprendidas en Myanmar, mediante una nueva estrategia provisional tendente a mejorar las condiciones de vida de la población", El Banco Mundial, disponible en http://www.bancomundial.org/es/news/press-release/2012/11/01/world-bank-groupsteps-up-support-reforms-myanmar-new-interim-strategy-improve-lives

European Commission (noviembre 3, 2012), José Manuel Barroso, President of the European Commission. Speech at the Myanmar Peace Centre, disponible en http://europa.eu/rapid/press-release_speech-12-771_en.doc

European Union External Action (marzo 5, 2013), The European Union and Burma/Myanmar-A new chapter in bilateral relations, disponible en http:// eeas.europa.eu/statements/docs/2013/131021_02_en.pdf

Fernández, Adrián (mayo 13, 2008), “¿Birmania o Myanmar?”, BBC, los blogs de $B B C$ Mundo, disponible en http://www.bbc.co.uk/blogs/spanish/2008/05/_birmania_o_myanmar.html

Frittin, Agnes, y O’Hara, Christopher (2011), “The Myanmar-Eu Roadmap. New Possibilities in a Changing Myanmar', Institute for Security and Development Policy Policy Brief, núm. 52, Institute for Security and Development Policy.

Frittin, Agnes, y Swanström, Niklas (2010), "European sanctions against Myanmar", Institute for Security and Development Policy Policy Brief, núm. 15, Institute for Security and Development Policy.

Haacke, Jürgen (2012), "Myanmar: Now a Site for Sino-Us Geopolitical Competition", IDEAS Reports, núm. SR015, London School of Economics. Han Shih, Toh (mayo 13, 2013), "China to remain in Myanmar even as Western firms arrive”, South China Morning Post, Business, disponible en http:// 
www.scmp.com/business/china-business/article/1236409/china-remaininfluential-myanmar-even-western-firms-arrive

Havel, Vaclav, y Tutu, Desmond (2005), "Threat to peace: A Call for the UN Security Council to Act in Burma", DLA Piper, Rudnick Gray Cary.

Ignatchenko, Igor (noviembre 15, 2012), "Myanmar: New Geopolitical Status", Strategic Culture Foundation, Columnists, disponible en http://www. strategic-culture.org/news/2012/11/15/myanmar-new-geopoliticalstatus.html

Khlopkov, Anton, y Konukhov, Dimitry (junio 29, 2011), "Russia, Myanmar and Nuclear Technologies", Center for Energy and Security Studies, disponible en http://ceness-russia.org/data/doc/myanmareng.pdf

Li, Chenyang (2012), "China-Myanmar Comprehensive Strategic Cooperative Partnership: A Regional Threat?”, Journal of Current Southeast Asian Affairs, 31(1), pp. 53-72.

Matsui, Motokatzu (marzo 2, 2014), "Myanmar expanding ties with Europe to reduce dependence on China", Nikkei Asian Review, Politics \& Economics, disponible en http://asia.nikkei.com/Politics-Economy/InternationalRelations/Myanmar-expanding-ties-with-Europe-to-reduce-dependenceon-China

Murphy, W. Patrick (febrero 28, 2013), "Human Rights in Burma", U. S. Deparment of State, Testimony, disponible en http://www.state.gov/p/eap/ rls/rm/2013/02/205487.htm

Myanmar President Office (noviembre 15, 2013), Joint press statement by co-chairs Catherine Aston, EU High Representative/Vice President of the Commission U Soe Thane, Union Minister from Ministry of President's Office, disponible en http://www.president-office.gov.mm/en/?q=print/2948

Naciones Unidas, Asamblea General (2011), Informe del Grupo de Trabajo sobre el Examen Periódico Universal: Myanmar, núm. A/HRc/17/9.

Power, Samantha (noviembre 9, 2012), "Supporting Human Rights in Burma", The White House, The White House Blog, disponible en http://www. whitehouse.gov/blog/2012/11/09/supporting-human-rights-burma

Ramachandran, Sudha (noviembre 8, 2011), "Russia targets China's clout in Myanmar", Asia Times Online, South Asia, disponible en http://www. atimes.com/atimes/South_Asia/mk08df01.html

Schearf, Daniel (mayo 28, 2013), "Burma's 2 Child Policy' for Muslims Criticized as Discriminatory", Voice of America, News, disponible en http://www. 
voanews.com/content/burma-two-child-policy-for-muslims-criticizedas-illegal-discriminatory/1669722.html

Sein, Thein (marzo 31, 2011), "President Thein Sein's Inaugural Speech", The New Light of Myanmar.

Slack, Megan (mayo 20, 2013), "President Obama Meets with President Thein Sein of Myanmar", The White House Blog, disponible en http://www. whitehouse.gov/blog/2013/05/20/president-obama-meets-presidentthein-sein-myanmar

Staggs Kelsall, Michelle (2009), “The New ASEAN Intergovernamental Commission on Human Rights: Toothless Tiger or Tentative First Step?”, Asia Pacific Issues, núm. 90, East West Center.

Stiglitz, Joseph E. (marzo 19, 2012), "Cambio en Birmania”, El País, Economía, disponible en http://economia.elpais.com/economia/2012/03/19/ actualidad/1332174052_987306.html

Tea, Billy (2010), "China and Myanmar Strategic Interests, Strategies and the Road Ahead", IPCS Research Papers, núm. 26, Institute of Peace and Conflict Studies.

The White House (mayo 17, 2012a), Statement by President on Burma, The White House, Washington, disponible en http://www.whitehouse.gov/ the-press-office/2012/05/17/statement-president-burma

- - (noviembre 19, 2012b), Remarks by President Barack Obama at the University of Yangon, disponible en http://www.whitehouse.gov/the-pressoffice/2012/11/19/remarks-president-obama-university-yangon

-_- (mayo 20, 2013), Remarks by President Obama and President Thein Sein of Myanmar After Bilateral Meeting, disponible en http://www.whitehouse. gov/blog/2013/05/20/

Thura, Myat (mayo 27, 2013), “Abe's Myanmar visit may help Japan parry China's influence", Japan Times, News, disponible en http://www.japantimes.co.jp/news/2013/05/27/national/abes-myanmar-visit-may-helpjapan-parry-chinas-influence/\#.UcsT4F-I5jo

Win, Swe (octubre 17, 2012), “The Jade War", New York Times, Opinión, disponible en http://latitude.blogs.nytimes.com/2012/10/17/clashingover-jade-ethnic-kachin-continue-to-oppose-the-myanmar-government/?_php=true\&_type=blogs\&_r=0 